\title{
Ring melanoma of the anterior chamber angle as a mimicker of pigmentary glaucoma
}

\section{Stadigh, Anni}

2017

Stadigh , A , Puska , P , Vesti , E , Ristimaki , A, Turunen , J A \& Kivela , T T 2017 , ' Ring melanoma of the anterior chamber angle as a mimicker of pigmentary glaucoma ', Survey of Ophthalmology , vol. 62 , no. 5 , pp. 670-676 . https://doi.org/10.1016/j.survophthal.2017.01.007

http://hdl.handle.net/10138/297935

https://doi.org/10.1016/j.survophthal.2017.01.007

publishedVersion

Downloaded from Helda, University of Helsinki institutional repository.

This is an electronic reprint of the original article.

This reprint may differ from the original in pagination and typographic detail.

Please cite the original version. 


\title{
Clinical pathologic reviews
}

\section{Ring melanoma of the anterior chamber angle as a mimicker of pigmentary glaucoma}

\author{
Anni Stadigh, $\mathrm{MD}^{a, *}$, Päivi Puska, MD, FEBO ${ }^{a}$, Eija Vesti, MD, FEBO ${ }^{b}$, \\ Ari Ristimäki, $\mathrm{MD}^{c}$, Joni A. Turunen, $\mathrm{MD}, \mathrm{FEBO}^{d}$, Tero T. Kivelä, $\mathrm{MD}, \mathrm{FEBO}^{d}$ \\ ${ }^{a}$ Glaucoma Service, Department of Ophthalmology, University of Helsinki and Helsinki University Hospital, Helsinki, \\ Finland \\ ${ }^{\mathrm{b}}$ Department of Ophthalmology, University of Turku, Turku University Central Hospital, Turku, Finland \\ ${ }^{c}$ Department of Pathology, HUSLAB, Research Programs Unit, University of Helsinki and Helsinki University \\ Hospital, Helsinki, Finland \\ ${ }^{\mathrm{d}}$ Department of Ophthalmology, Ocular Oncology Service and Ophthalmic Pathology Laboratory, University of \\ Helsinki and Helsinki University Hospital, Helsinki, Finland
}

\section{A R T I C L E I N F O}

Article history:

Received 23 September 2016

Received in revised form 18 January

2017

Accepted 23 January 2017

Available online 1 February 2017

Stefan Seregard and Hans,

Grossniklaus, Editors

Keywords:

unilateral glaucoma

pigment dispersion

uveal melanoma

ring melanoma of anterior chamber angle

secondary angle closure glaucoma

\begin{abstract}
A B S T R A C T
A 19-year-old man noticed blurred vision in his right eye. He had an intraocular pressure of 60 versus $12 \mathrm{mmHg}$ in the fellow eye. He was initially diagnosed with an atypical, advanced pigmentary glaucoma. The intraocular pressure did not respond to maximal medication, deep sclerectomy, goniopuncture, and 2 cyclophotocoagulations. Sixteen months after presentation, malignancy was first suspected, and the eye was enucleated. A ring melanoma of the anterior chamber angle was confirmed by the histopathologic examination. Normal nuclear staining for breast cancer 1 gene (BRCA1)-associated protein 1 suggested that the tumor was likely of disomy 3 type with a favorable prognosis. No local or systemic recurrence has developed within 4 years. A literature review of this rare type of minimal volume diffuse uveal melanoma identified 18 additional patients. The initial diagnosis in 18 of the 19 patients with a ring melanoma of the anterior chamber angle was unilateral glaucoma with a median intraocular pressure of $40 \mathrm{mmHg}$ and an age range of 16-76 years. Liver metastasis developed in 5 of 12 patients older than 45 years. This rare subtype is estimated to account for $0.05 \%-0.16 \%$ of all uveal melanomas.
\end{abstract}

(c) 2017 Elsevier Inc. All rights reserved.
1.

\section{Case report}

A 19-year-old man presented with a 1-week history of blurred vision without pain in his right eye. He had no history of ocular injury. His visual acuity was counting fingers at 5 feet in the affected eye and 20/20 in the fellow eye. The intraocular pressures (IOP) were $60 \mathrm{mmHg}$ and $12 \mathrm{mmHg}$, respectively. Mild conjunctival hyperemia was present. The cornea was clear with no Krukenberg spindle. The anterior chamber was deep with a few pigmented cells in the aqueous. On gonioscopy, the chamber angle was heavily pigmented. The iris did not transilluminate. The lens was clear, but some pigment

\footnotetext{
* Corresponding author: Anni Stadigh, MD, Department of Ophthalmology, University of Helsinki and Helsinki University Hospital, Haartmaninkatu 4 C, PL 220, FI-00029 HUS, Helsinki, Finland. Tel.: +358 50327 2413; fax: + 358947175100.

E-mail address: anni.stadigh@hus.fi (A. Stadigh).

0039-6257/\$ - see front matter @ 2017 Elsevier Inc. All rights reserved. 
dispersion on the anterior capsule was noted. The optic disk was almost totally excavated. Magnetic resonance imaging of the orbits and brain, iris fluorescein angiography, and examination of the fellow eye were all unremarkable. He was diagnosed with advanced, atypical unilateral pigmentary glaucoma by a glaucoma specialist, and topical IOP lowering medication was prescribed.

The IOP remained high at $31 \mathrm{mmHg}$ with up to 4 topical medications (prostaglandin analog, carbonic acid inhibitor, and a brimonidine/timolol combination). Six months after his first visit, he underwent deep sclerectomy. The filtration was considered insufficient, and laser goniopuncture was performed unsuccessfully. Because the IOP still remained at $32 \mathrm{mmHg}$ on topical medications and oral carbonic anhydrase inhibitor $250 \mathrm{mg}$ t.i.d, the eye was cyclophotocoagulated a month later. The inferior sector received 20 applications of $650 \mathrm{~mW}$ applied for 8 seconds. Normotension was now achieved. After 6 months, the IOP was $30 \mathrm{mmHg}$; thus, a second cyclophotocoagulation was performed. Now the temporal sector was treated with 20 applications. One month after the procedure, the IOP was $46 \mathrm{mmHg}$, and the patient was referred to an ophthalmic surgeon experienced in Molteno implant surgery. The atypical pigment dispersion caught his attention. On the same day, the patient was referred to the center for ocular oncology in the Helsinki University Eye Hospital.

The visual acuity of the right eye was 20/400, and the IOP was $49 \mathrm{mmHg}$ on his current medications. The corneal endothelium showed minor pigment dispersion. The iris had a few pigment flecks that resembled small iris nevi and freckles (Fig. 1A). The anterior lens capsule showed prominent pigment dispersion. On gonioscopy, the angle was heavily pigmented but had an otherwise normal appearance except inferiorly, where it was velvetlike with several dilated capillaries and some broad anterior synechiae (Fig. 1B). Superiorly, the angle was grayish with less abundant pigment dispersion. A visual field from the referring hospital showed extensive glaucomatous damage (Fig. 1B, inset). The optic disc was almost totally excavated (Fig. 1C). As examined with an ultrasound biomicroscope, the ciliary body and iris appeared normal in all quadrants with no evidence of a tumor (Fig. 1D and $E$ ).

The absence of any typical findings of pigmentary glaucoma, such as bilaterality, Krukenberg spindle, a deep anterior chamber, and transillumination defects in the iris, together with the refractory nature of the IOP, were strongly suggestive of a ring melanoma of the anterior chamber angle. ${ }^{6}$ The by now almost blind eye was enucleated 18 months after the first symptoms. The macroscopic examination showed no sign of the tumor (Fig. 1F ). In the histopathologic examination, tumor cells were found in the chamber angle and the trabecular meshwork and also focally infiltrating the ciliary body band (Fig. 2A-C). Both small epithelioid-like and plump spindle-shaped melanoma cells were present, and the infiltrative growth pattern of single noncohesive cells at the base of the ciliary body and in the iris stroma also favored a partially epithelioid-like nature of the melanoma (Fig. 2D-F). Cells were also found in the iris root, anterior iris stroma, and adjacent deep scleral lamellae (Fig. 3A). There were tumorinfiltrating macrophages on the lens capsule where melanoma cells were scarce (Fig. 3B) and in the ciliary body and trabecular meshwork (Fig. 3C). The diagnosis of a ring melanoma of the anterior chamber angle was confirmed. The tumor cells showed normal nuclear immunoreactivity for breast cancer 1 gene (BRCA1)-associated protein 1 (BAP1; Fig. 3D-F ). No germline mutation in the BAP1 gene was found in peripheral blood lymphocyte DNA (for methodology, $\mathrm{see}^{29}$ ). During a follow-up of 4 years, no local recurrence or metastases have been found.

\section{Discussion}

\subsection{Epidemiology}

A ring melanoma of the anterior chamber angle, ${ }^{6}$ alternatively referred to as a trabecular meshwork melanoma, ${ }^{28}$ is an infrequent, but distinct, minimal volume diffuse uveal melanoma. It infiltrates the chamber angle in a ring-like pattern, typically approaching $360^{\circ}$. It has minimal iris and ciliary body involvement and thus cannot be reliably diagnosed with ultrasound biomicroscopy, unlike common ring melanomas of the ciliary body and iris. ${ }^{6,28}$ The diagnosis is clinical and is based on gonioscopy and a high suspicion in a setting that mimics unilateral pigmentary glaucoma. Unilateral pigmentary glaucoma without evidence of pigment dispersion in the fellow eye is in itself rare, but may occur after angle recession. ${ }^{20,24}$

We conducted a PubMed search and found 1 referral-based case series of 14 patients among 8800 uveal melanomas ${ }^{6}$ plus 4 single case reports of this entity. ${ }^{2,5,11,19}$ In the case series, this type of diffuse tumor accounted for $0.16 \%$ (95\% confidence interval: 0.09-0.27) of uveal melanomas. ${ }^{6}$ In our populationbased database, the patient we describe is the first case among 1973 primary uveal melanomas $(0.05 \%$; $95 \%$ confidence interval: 0.01-0.28). Given that the estimated 7000 uveal melanomas are diagnosed annually worldwide, ${ }^{16}$ these 2 estimates would translate to between 1 and 19 ring melanomas of the anterior chamber angle per year.

\subsection{Clinical and histopathologic characteristics}

Table 1 summarizes the clinical and histopathologic findings of the 19 patients diagnosed with a ring melanoma of the anterior chamber angle. The median age of these patients was 59 years (range: 16-76). Because the cumulative frequency of having uveal melanoma diagnosed increases notably after the age of $40-45$ years, ${ }^{18}$ the patients are subdivided in 2 age groups, those younger and older than 45 years. The median age was 24 years (range: 16-40) and 61 years (range: $52-76$ ), respectively. The median diagnostic delay was shorter in the younger age group (2 vs 6 months), possibly because glaucoma in the younger age group is rare, and an underlying disease may thus be sought more actively.

There were no significant differences between the 2 groups concerning the clinical trabecular meshwork involvement (median: 11 vs 10 clock hours, the younger vs the older age group), iris root involvement ( $83 \%$ vs $73 \%$ ), histologic pars plicata involvement (67\% vs $73 \%$ ), and histological extrascleral extension ( $29 \%$ vs $36 \%$ ). 

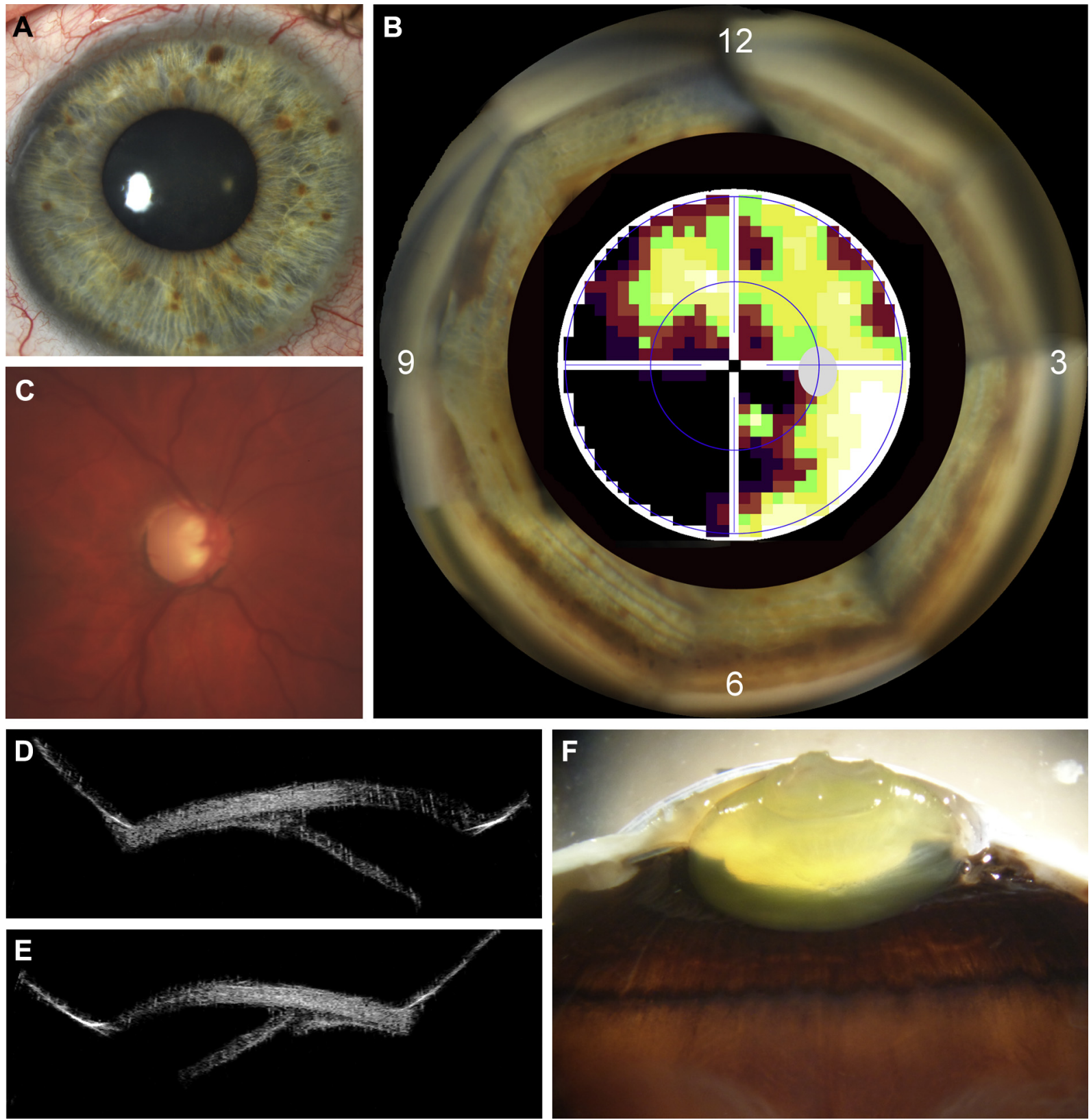

Fig. 1 - A: Slit-lamp image showing innocuous appearing small nevus and freckle-like patches on the anterior iris stroma. B: Composite gonioscopic images showing the pigmented chamber angle. Inset, Octopus visual field consistent with advanced glaucoma. C: The optic disk is almost totally excavated. D: Ultrasound biomicroscopy image of the inferior and E: superior part of the ciliary body showing no tumor and only a blunt angle. F: Macroscopic examination shows no tumor.

\subsection{Prognosis}

The original case series that laid the foundation for diagnosing a ring melanoma of the anterior chamber angle postulated that the prognosis of a ring melanoma of the anterior chamber angle in general might be poor because a high IOP combined with chamber angle involvement might promote hematogenous spread. ${ }^{6}$ In practice, 5 of 18 patients (29\%) with follow-up data have developed liver metastasis, but the age of these 5 patients ranged from 59 to 76 years; that is, all were in the older age group.
Iris melanomas are proportionally more common than ciliary body and choroidal ones in children and young adults. ${ }^{26}$ Given that 5 of the patients (26\%) with a ring melanoma of the anterior chamber angle have been younger than 30 years at the time of diagnosis, it also seems that it is relatively more common among the young, suggesting that some of these tumors may derive from irideal melanocytes. Iris melanomas have a better average survival prognosis than more posterior uveal melanomas. ${ }^{27}$ This would be consistent with the observation that liver metastases have developed only in the older age group. In addition to a potential iris origin, however, 

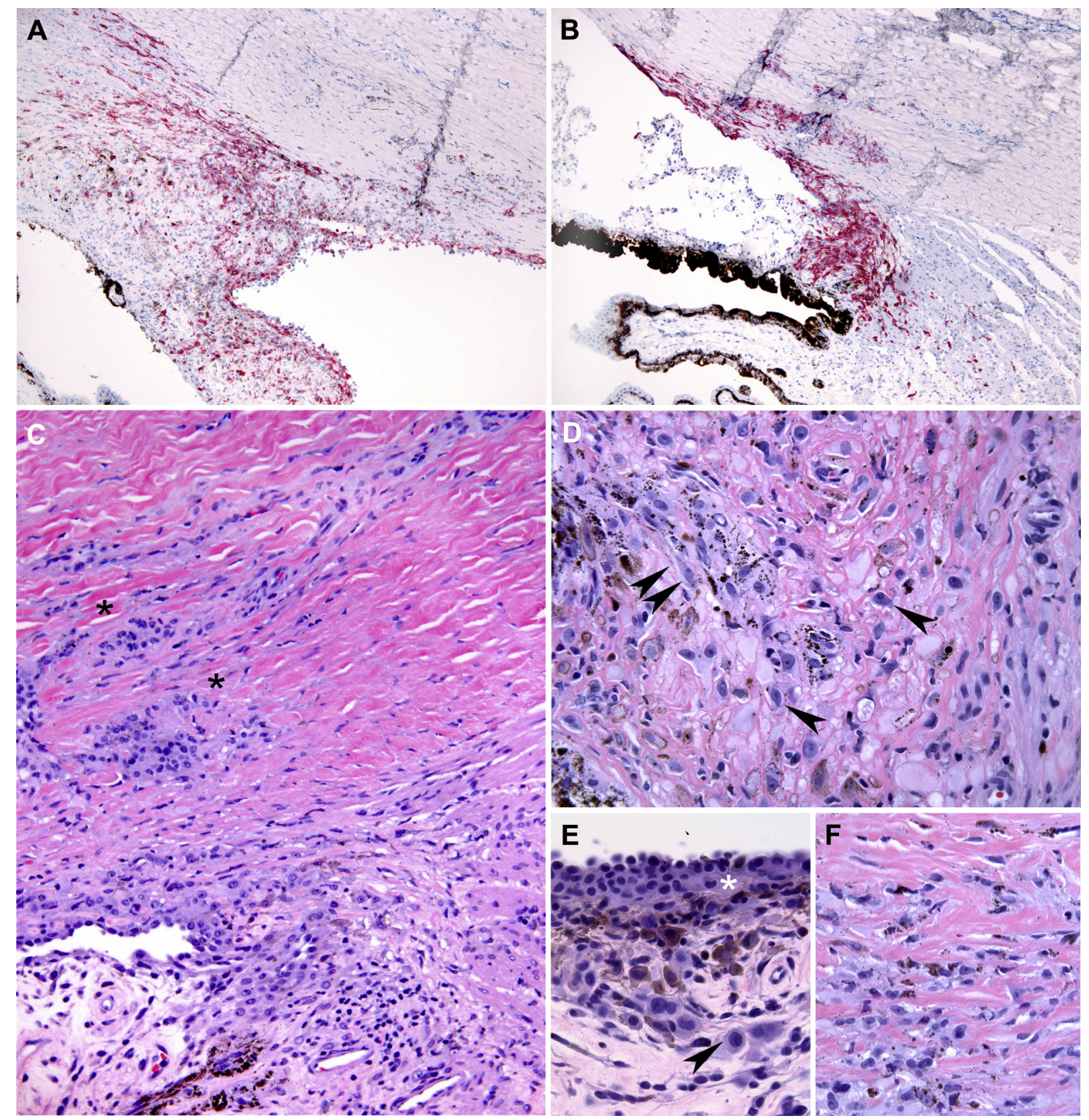

Fig. 2 - A: The inferior cross section and B: the superior cross section of the chamber angle showing infiltration of trabecular meshwork, ciliary body band, iris root, and iris stroma by melanoma cells highlighted by red stain. C: Infiltration of the sclera along collector channels (asterisks). D: Noncohesive small amelanotic epithelioid-like melanoma cells (arrowheads) with large nucleoli infiltrate diffusively the base of the ciliary body. A group of plump spindle-shaped, sparsely pigmented melanoma cells (double arrowheads) are also seen. E: Small amelanotic epithelioid-like melanoma cells (asterisk) grow on the surface of the iris as a sheet from which larger non-pigmented (arrowheads) and pigmented tumor cells infiltrate the iris stroma. F: Mostly plump spindle-shaped melanoma cells infiltrate the trabecular meshwork area. (A-B, immunohistochemical staining for MelanA, 60 X; C, H\&E, 170 X; D-F, H\&E, 250 X.)

young age in itself might improve prognosis because young patients with uveal melanoma in general have a lower risk for metastases than middle-aged and older adults..$^{1,13}$

One patient, aged 16 years, developed ipsilateral parotid lymph node metastases. ${ }^{11}$ He had massive extraocular extension and orbital invasion of the tumor, and histopathologic examination revealed an advanced epithelioid cell-type melanoma. Lymphatic spread of uveal melanoma is extremely rare due to lack of intraocular and orbital lymphatic vessels. Anterior location of ring melanomas allows lymph node metastases after tumor extension to the conjunctiva lymphatic vessels. ${ }^{7,9}$ Lymph node metastasis have also been seen after glaucoma surgery. ${ }^{3,30}$ No estimate can yet be made whether or not lymph node metastases will be more common from uveal melanomas of the anterior chamber angle, although the anterior location of the tumor is an obvious risk 
A

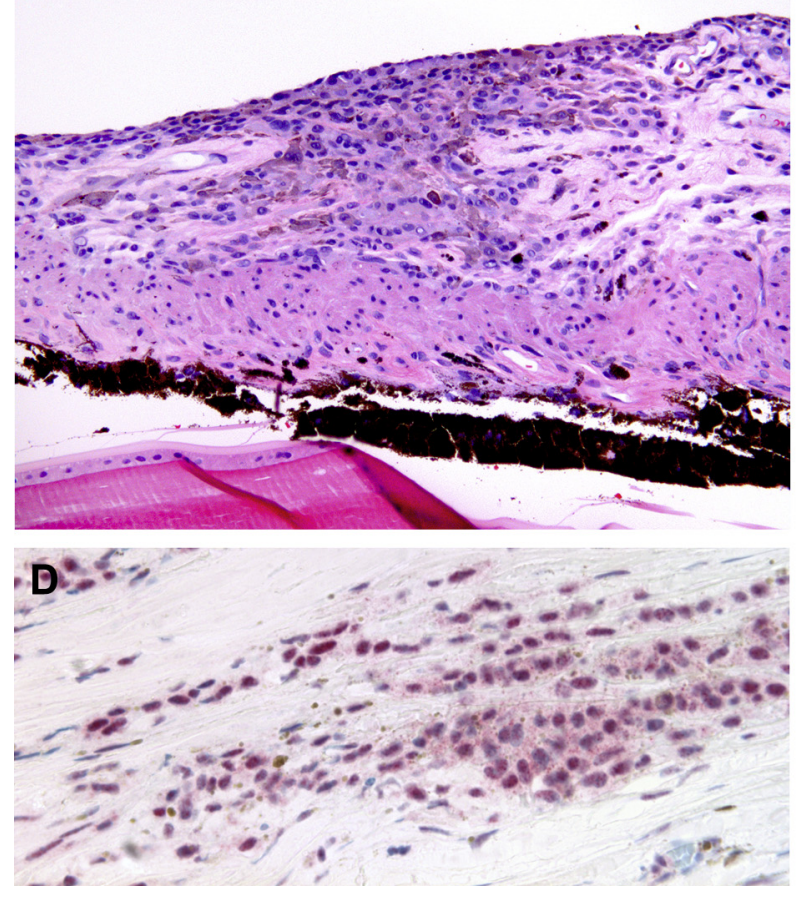

B

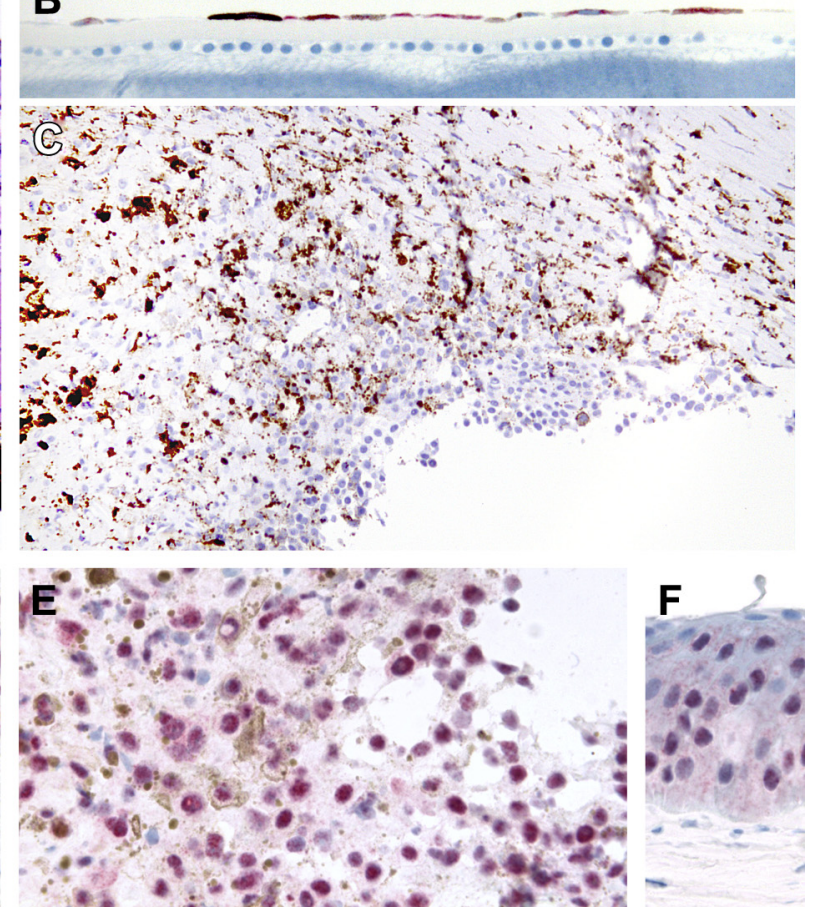

Fig. 3 - A: Infiltration of the anterior iris stroma which gave the appearance of a small iris nevus. B: Immunopositive macrophages spread on the lens capsule. $C$ : Macrophages around and within the tumor in the ciliary body and chamber angle highlighted by brown stain. D: BRCA-1 associated protein 1 (BAP1) is localized to the nuclei of the tumor cells highlighted by red stain within collector channels and $E$ : in the ciliary body band of the chamber angle as it does in normal tissues such as $F$, the corneal epithelium in the same eye. (A, H\&E, $130 \mathrm{X}$; B, immunohistochemical staining, 220X; C: immunohistochemical staining for CD68 antigen, $170 \mathrm{X}$; and $D-F$, immunohistochemical staining for BAP1, $250 \mathrm{X}$.)

factor, suggesting that review of regional lymph nodes is advisable.

Regarding the prognosis, the normal nuclear BAP1 immunohistochemistry in our patient favors a disomy 3 melanoma with limited metastatic potential and is encouraging, especially because tumor extension to the chamber angle that we observed is in general associated with a higher rate of metastasis from iris melanomas. ${ }^{15,27}$ For over 20 years, monosomy 3 is known to be related to poorer prognosis in uveal melanoma. ${ }^{23}$ The tumor suppressor gene BAP1 has been mapped to the chromosome, ${ }^{3,10}$ and irrespective of chromosome 3 status, mutations in BAP1, which typically abolish BAP1 immunoreactivity, are associated with metastatic progression and poorer survival. ${ }^{10,14,17,25}$

\subsection{Differential diagnosis}

The initial diagnosis in 18 of the 19 patients with a ring melanoma of the anterior chamber angle, including our patient, was unilateral glaucoma. One patient was initially diagnosed to have an iris nevus. Early diagnosis is challenging because the rise of the IOP is usually gradual and painless, and visual symptoms are late findings. The median IOP at diagnosis was $40 \mathrm{mmHg}$ (range: $24-62$, IOP level was not mentioned in 1 patient. $\left.{ }^{11}\right)$. There was no significant difference in median IOP between the younger and the older age group $(36 \mathrm{mmHg}$, range: 24-49, vs $40 \mathrm{mmHg}$, range: $25-62$ ). Of note, none of the patients achieved a normal IOP level when treated with medications or surgical procedures. Twelve of the 19 patients $(63 \%)$ had a visual acuity of $20 / 40$ or better at the time of diagnosis.

Our patient was initially diagnosed as having unilateral pigmentary glaucoma, although no traditional diagnostic criteria were present, except that the patient was a young man. Typical findings in pigment dispersion glaucoma include Krukenberg spindle on the corneal endothelium, a deep anterior chamber, transillumination defects in the iris, and a richly pigmented trabecular meshwork, and it is characteristically a bilateral condition. ${ }^{21}$ Secondary glaucoma can be the first sign of an intraocular melanoma, , ,8,12,22,31 especially of a ring melanoma of the anterior chamber angle that may not yet be well known among glaucoma specialists. A further problem in reaching the correct diagnosis is that the usual diagnostic criteria of uveal melanoma are not met. This factor should be kept in mind when faced with a unilateral or highly asymmetric glaucoma, especially when the pressure does not respond to treatment and when clinical findings are atypical of pigmentary glaucoma.

Our patient had undergone glaucoma filtration surgery, which may have altered the prognosis. Filtration surgery is not recommended in eyes with uveal melanoma not to risk extraocular spread of the tumor. Routine biopsy obtained in conjunction with filtration surgery, on the other hand, might have revealed the tumor earlier. It would be advisable for glaucoma surgeons to consider submitting trabeculectomy 
Table 1 - Clinical and histopathologic findings in patients with a ring melanoma of the anterior chamber angle arranged according to age at diagnosis

Reference/ Age when Diagnostic Claucoma Metastases Trabecular meshwork tis rot Cell type Extrascleral Pars plicata

case glaucoma

delay

surgery

involvement (clock hours, involvement

(clinical)

extension

involvement
(histological) $^{\mathrm{a}}$

Follow-up diagnosed/gender (months) clinical)

(clinical)

time

\begin{tabular}{|c|c|c|c|c|c|c|c|c|c|c|}
\hline \multicolumn{11}{|c|}{ Age $<45$ years } \\
\hline 11 & $16 / \mathrm{M}$ & 72 & Trabeculectomy & $\begin{array}{c}\text { Regional } \\
\text { lymph node }\end{array}$ & N/A & N/A & Epithelioid & Yes & N/A & 72 \\
\hline Present & 19/M & 18 & $\begin{array}{l}\text { Deep } \\
\text { sclerectomy }\end{array}$ & No & 10 & Yes & $\begin{array}{l}\text { Small } \\
\text { epithelioid }\end{array}$ & No & Yes & 48 \\
\hline $6 / 14$ & $23 / F$ & 1 & No & No & 8 & Yes & Mixed & No & Yes & 23 \\
\hline $6 / 1$ & $24 / F$ & 1 & No & No & 12 & No & Spindle & No & Yes & 29 \\
\hline $6 / 2$ & 29/M & 1 & No & No & 10 & Yes & Mixed & No & Yes & 33 \\
\hline $6 / 3$ & $36 / \mathrm{M}$ & 2 & No & No & 12 & Yes & Mixed & Yes & No & 29 \\
\hline $6 / 4$ & $40 / \mathrm{F}$ & 12 & No & No & 12 & Yes & Spindle & No & No & 41 \\
\hline \multicolumn{11}{|c|}{ Age $\geq 45$ years } \\
\hline $6 / 13$ & $52 / \mathrm{M}$ & 10 & No & No & 8 & No & Mixed & N/A & N/A & 53 \\
\hline $6 / 5$ & $58 / \mathrm{M}$ & 18 & No & No & 8 & Yes & Spindle & No & Yes & 225 \\
\hline $6 / 6$ & $59 / \mathrm{F}$ & 1 & No & Hepatic & 8 & No & Epithelioid & Yes & Yes & 70 \\
\hline $6 / 7$ & 59/M & 1 & No & No & 12 & Yes & Mixed & No & No & 54 \\
\hline $6 / 8$ & $60 / F$ & 20 & No & No & 12 & Yes & Spindle & No & Yes & 1 \\
\hline 19 & $60 / \mathrm{M}$ & N/A & N/A & Hepatic & 12 & Yes & Mixed & No & Yes & 48 \\
\hline $6 / 9$ & $61 / \mathrm{M}$ & 6 & No & Hepatic & 12 & Yes & Mixed & Yes & Yes & 128 \\
\hline $6 / 10$ & $65 / \mathrm{M}$ & 5 & No & No & 10 & Yes & Mixed & No & Yes & 1 \\
\hline $6 / 11$ & $70 / \mathrm{F}$ & 26 & No & No & 12 & Yes & Mixed & No & No & 54 \\
\hline $5 / 1$ & 73/M & 4 & Iridectomy & N/A & 9 & Yes & Mixed & Yes & Yes & N/A \\
\hline 2 & 74/M & 24 & No & Hepatic & N/A & N/A & Mixed & Yes & Yes & 12 \\
\hline $6 / 12$ & $76 / \mathrm{M}$ & 1 & No & Hepatic & 8 & No & Mixed & No & No & 37 \\
\hline
\end{tabular}


and sclerectomy specimens for histopathologic study in atypical cases.

\section{Conclusion}

A uveal melanoma of the anterior chamber angle is a rare tumor that can mimic unilateral glaucoma. There should be high suspicion of a malignancy in diagnosing an atypical unilateral glaucoma.

\section{Literature search}

We conducted a literature search using PubMed with search terms "uveal melanoma," "chamber angle," and "trabecular meshwork." References cited in the articles were included in the search, including non-English ones.

\section{Disclosure}

The authors declare no conflict of interest.

\section{Acknowledgments}

This study was supported in part by research grants from the Sigrid Jusélius Foundation,Finland, and the Helsinki University Hospital Research Fund (TYH 2013316).

\section{R E F E R E N C E S}

1. Al-Jamal RT, Cassoux N, Desjardins L, et al. The pediatric choroidal and ciliary body melanoma study: a survey by the European Ophthalmic Oncology Group. Ophthalmology. 2016;123(4):898-907

2. Allaire GS, Corriveau C, Boileau M. Ring melanoma of the anterior uvea presenting as unilateral neovascular glaucoma. Can J Ophthalmol. 1997;32(5):338-41

3. Ardjomand N, Komericki P, Langmann G, et al. Lymph node metastases arising from uveal melanoma. Wien Klin Wochenschr. 2005;117(11-12):433-5

4. Bianciotto C, Saornil MA, Muinos Y, et al. Ocular hypertension as the principal indicator of onset of uveal melanoma. Arch Soc Esp Oftalmol. 2005;80(1):27-34

5. Chaudhry IM, Moster MR, Augsburger JJ. Iris ring melanoma masquerading as pigmentary glaucoma. Arch Ophthalmol. 1997;115(11):1480-1

6. Demirci H. Ring melanoma of the anterior chamber angle: a report of fourteen cases. Am J Ophthalmol. 2001;132(3):336-42

7. Dithmar S, Diaz CE, Grossniklaus HE. Intraocular melanoma spread to regional lymph nodes: report of two cases. Retina. 2000;20(1):76-9

8. Escalona-Benz E, Benz MS, Briggs JW, Budenz DL, Parrish RK, Murray TG. Uveal melanoma presenting as acute angleclosure glaucoma: Report of two cases. Am J Ophthalmol. 2003;136(4):756-8

9. Grossniklaus HE, Wilson MW, Barron BC, Lynn MJ. Anterior vs posterior intraocular melanoma. metastatic differences in a murine model. Arch Ophthalmol. 1996;114(9):1116-20
10. Harbour JW, Onken MD, Roberson ED, et al. Frequent mutation of BAP1 in metastasizing uveal melanomas. Science. 2010;330(6009):1410-3

11. Harris MS, Harris GJ, Simons KB, Campbell BH. Massive extraocular extension and parotid lymph node metastasis of uveal melanoma. Ophthal Plast Reconstr Surg. 2007;23(5):430-2

12. Johnson DL. Uveal melanoma masquerading as pigment dispersion glaucoma. Arch Ophthalmol. 2008;126(6):868-9

13. Kaliki S, Shields CL, Mashayekhi A, Ganesh A, Furuta M, Shields JA. Influence of age on prognosis of young patients with uveal melanoma: a matched retrospective cohort study. Eur J Ophthalmol. 2013;23(2):208-16

14. Kalirai H, Dodson A, Faqir S, Damato BE, Coupland SE. Lack of BAP1 protein expression in uveal melanoma is associated with increased metastatic risk and has utility in routine prognostic testing. Br J Cancer. 2014;111(7):1373-80

15. Khan S, Finger PT, Yu GP, et al. Clinical and pathologic characteristics of biopsy-proven iris melanoma: a multicenter international study. Arch Ophthalmol. 2012;130(1):57-64

16. Kivela $T$. The epidemiological challenge of the most frequent eye cancer: retinoblastoma, an issue of birth and death. Br J Ophthalmol. 2009;93(9):1129-31

17. Koopmans AE, Verdijk RM, Brouwer RW, et al. Clinical significance of immunohistochemistry for detection of BAP1 mutations in uveal melanoma. Mod Pathol. 2014;27(10):1321-30

18. Kujala E, Makitie T, Kivela T. Very long-term prognosis of patients with malignant uveal melanoma. Invest Ophthalmol Vis Sci. 2003;44(11):4651-9

19. Manschot WA. Ring melanoma. Arch Ophthalmol. 1964;71:625-32

20. McKinney JK, Alward WL. Unilateral pigment dispersion and glaucoma caused by angle recession. Arch Ophthalmol. 1997;115(11):1478-9

21. Niyadurupola N, Broadway DC. Pigment dispersion syndrome and pigmentary glaucoma-a major review. Clin Exp Ophthalmol. 2008;36(9):868-82

22. Othman IS, Assem M, Zaki IM. Secondary glaucoma as initial manifestation of uveal melanoma. Saudi J Ophthalmol. 2013;27(3):203-8

23. Prescher G, Bornfeld N, Hirche H, Horsthemke B, Jockel KH Becher R. Prognostic implications of monosomy 3 in uveal melanoma. Lancet. 1996;347(9010):1222-5

24. Ritch R, Alward WL. Asymmetric pigmentary glaucoma caused by unilateral angle recession. Am J Ophthalmol. 1993;116(6):765-6

25. Shah AA, Bourne TD, Murali R. BAP1 protein loss by immunohistochemistry: a potentially useful tool for prognostic prediction in patients with uveal melanoma. Pathology. 2013;45(7):651-6

26. Shields CL, Kaliki S, Arepalli S, et al. Uveal melanoma in children and teenagers. Saudi J Ophthalmol. 2013;27(3):197-201

27. Shields CL, Kaliki S, Shah SU, Luo W, Furuta M, Shields JA. Iris melanoma: features and prognosis in 317 children and adults. J AAPOS. 2012;16(1):10-6

28. Shields J, Shields C. Melanocytic tumors of iris stroma. In Intraocular tumors. An atlas and textbook. Philadelphia, Lippincott Williams \& Wilkins; 2008, pp 13-36

29. Turunen JA, Markkinen S, Wilska R, et al. BAP1 germline mutations in finnish patients with uveal melanoma. Ophthalmology. 2016;123(5):1112-7

30. Zakka KA, Foos RY, Sulit H. Metastatic tapioca iris melanoma. Br J Ophthalmol. 1979;63(11):744-9

31. Zhao M, Mu Y, Dang Y, Zhu Y. Secondary glaucoma as initial manifestation of ring melanoma: A case report and review of literature. Int J Clin Exp Pathol. 2014;7(11):8163-9 